\title{
Research on Exploring the Innovation Strategy of College English Translation Teaching Based on Functional Translation Theory
}

\author{
Yaoda Zheng \\ Wenzhou Business College, School of Foreign Languages and International Trade, Wenzhou, 325035
}

Keywords: functional translation theory; College English; translation teaching innovation

\begin{abstract}
As a practical subject, English occupies an increasingly important position in the field of national education. This paper analyzes the status quo of English translation teaching in colleges and universities in China, and puts forward suggestions for improving the establishment of teaching supervision and evaluation mechanisms for teaching, the actual translation teaching innovation, the reform and innovation of the teaching model, and other countermeasures for English translation teaching in innovative colleges and universities.
\end{abstract}

\section{Introduction}

With the gradual implementation of the new curriculum reform policy, the people are increasingly concerned about the cultivation of their scientific and cultural qualities. This article begins with a brief description of the advantages and features of the functional translation theory. Then it presents the current situation of college English translation teaching based on the functional translation theory. Finally, it focuses on exploring the strategies of English translation teaching based on the functional translation theory.

\section{Analysis of the Advantages and Features of Functional Translation Theory}

On the one hand, English classroom teaching based on translation theory can express the original author's ideas in another language through the transformation of language and sentence patterns, and effectively combine the cultural factors between the languages and the translation work. The translation of articles from the perspective of the article has important practical significance for communication and communication among various cultures. On the other hand, functional translation is different from traditional English translation. Its focus is on the author's cultural level and actual translation. The combination of teaching makes the translated articles more creative and subjective, and plays an important role in the cultivation of students' language creativity [1].

\section{The Current Status of College English Translation Teaching Based on Functional Translation Theory}

First, colleges and universities pay little attention to the English translation classroom. At this stage, with the gradual deepening of the new curriculum reform policy, the teaching subjects of each school have shown a variety of development trends. Although each school has set up an English subject in teaching, it still stays at the level of grammar in teaching models and teaching contents. , reading comprehension, composition writing, etc., ignore the importance of translation for the growth of English learning ability. At the same time, although some schools have realized the importance of the English translation classroom for improving the efficiency of English learning and improving the effectiveness of English learning, they have not set specific subjects for the translation classroom in specific classroom teaching. Students learn English translation knowledge. Only from the elective subjects to understand, and there is no focus on targeted translation studies, so English translation in English teaching activities are often in a weak position [2].

Second, major universities and colleges are boring and single-formed in English classroom teaching. At present, although English teachers in some colleges and universities in our country 
have gradually changed their teaching models and teaching concepts, and have realized the importance of translation classroom teaching for students' comprehensive learning ability in English, they are in the process of implementation. The lack of relevant experience in the translation classroom teaching shows that the content of the teaching content is boring and the teaching model is simple and stereotyped, which greatly affects students' enthusiasm for learning English. The single main mode of classroom teaching is that it does not combine the translation knowledge of English teaching with the actual teaching situation. For example, when a teacher is explaining practice makes perfect, literal meaning is practice can make it more perfect, but such a translation model makes the sentence more rigid and rigid, and the maturity of translation can make English sentence The expression of the meaning of the ingredients can also make English sentences more vivid and creative. Therefore, the monotony of the English classroom translation model is one of the important reasons for the long-term semi-stagnant development of English translation classroom teaching [3].

Third, the teaching experience of English teachers in major universities is insufficient. At the present stage, colleges and universities pay too much attention to the professional background and academic level of teaching in the recruitment of teachers, and then neglect to consider the teaching experience of teachers; In addition, after the recruitment of teachers, there is no relevant knowledge of the teacher's translation classroom teaching mode. Theoretical training leads to teachers' low literacy, which in turn affects the effectiveness of English translation classroom teaching.

\section{The Factors Affecting the Innovation of College English Translation Teaching}

English teachers in universities are the main players and organizers who can translate classroom teaching. The performance of classroom teaching will directly affect classroom teaching efficiency and teaching quality. Teachers' performance of English translation classroom can be divided into the following aspects: First, The teacher's choice of classroom teaching mode and classroom teaching methods is affected by the traditional irrigation-based teaching thinking mode. The teaching of English translation classrooms is focused on the instillation of theoretical knowledge, thus ignoring the social practice of English translation teaching, and at the same time In order to improve the accuracy of students' English translation, English teachers in colleges and universities often allow classmates to compare their own translations with reference answers, and on the basis of this, refer to the reference answer for modification. This kind of content is boring in a single form. The classroom teaching mode lacks effective communication and interaction between teachers and students, which is not only unfavorable to the innovation of teacher's classroom teaching mode and teaching philosophy, but also affects college students' enthusiasm for classroom learning. Second, there is a lack of teacher-student interaction in classroom teaching. Awareness for students in the classroom changes in actual classroom performance and the ability to translate not fully understood, cannot be classified teaching for the personality development of students, thereby affecting innovation and enhance the quality of teaching English translation classroom [4].

With the gradual implementation of the new curriculum reform policy, students gradually become the subject of English translation classroom teaching. The mastery of their basic knowledge of English learning has a huge impact on the teaching of English translation classes. In recent years, with the growth of the number of students in universities, major universities have ushered in a large number of students in different regions. Due to different educational environments and different learning abilities, they have severe polarization in English learning. Phenomenon, which in turn severely increases the difficulty of teacher's translation practice teaching; at the same time, some students are mentally relaxed and relaxed due to their recent entry into university doors and often pay attention to other more relaxed subjects in the classroom. In terms of learning, even some students will suffer from absenteeism and skipping classes. These phenomena have a direct impact on the effectiveness of college English translation classroom teaching [5]. 


\section{The Innovation Strategy of College English Translation Teaching Based on Functional Translation Theory}

\subsection{Reform and Innovation of Teachers' Teaching Model.}

If we want to effectively introduce translation teaching in English classroom teaching, English teachers in colleges and universities will need to change and innovate the teaching model and teaching philosophy. We will integrate the interesting teaching elements into the classroom teaching and inspire students to learn English translation.

First of all, English, as a practical discipline, has different forms of language expression in different contexts. In this context, teachers must integrate discourse functions and contextual functions in English classroom translation teaching. Based on the contextual context, the English expression ability is more life-like and vivid; at the same time, English teachers must use the English syllabus to effectively guide the students' translation teaching. Students are fully aware of the importance of context in translation teaching and apply it to the learning process of English translation [6].

Second, teachers must emphasize the overall principles of English translation when teaching English classes in the classroom. Translation teaching in English is definitely not just a translation of a sentence or a word, but the overall coordination of the translated content. Therefore, when teachers innovate in teaching programs, they should focus on the overall coordination of English translation to ensure the smoothness and logicality of sentences. At the present stage, English teachers mostly use sentence-by-sentence translation when translating teaching, and then combine the translated sentences into fluent paragraphs. This kind of translation model can translate English-language articles in detail and specifically, but ignores them. The overall coordination of translation of English articles, so English teachers in the translation of articles, according to the actual situation of the article can be selectively translated without the need for word-by-word translation, in order to ensure that the article has reference significance.

\subsection{Innovation in Practical Translation Teaching.}

First, college English teachers need to combine the actual teaching context of English in their translation teaching. As a practical language and English, English has many synonyms in the translation of words. In the process of English translation, choosing appropriate words and explanations according to different contexts can better reflect the context at that time. More fit. For example, when a teacher translates a sentence "I don't like learning" when teaching Chinese to English, it can be translated as I don't like studying. However, English translation needs to be combined with contextual context. The degree of discussion and research can be based on the degree of dislike, hate and other words, so that the sentence meets the context and the situation at that time.

Second, English teachers in colleges and universities need to pay attention to the transformation of sentence patterns in the classroom teaching of translation. English teaching is different from Chinese teaching. There are many sentence patterns in the expression of sentences. They mainly include the active and passive voices, attributive clauses, and adverbial clauses. Therefore, when English teachers teach in the translation classroom, they should pay attention to the conversion of sentence patterns so that both Chinese and English can be more smoothly communicated and expressed in the conversion [7].

Third, teachers should also pay attention to the use of rhetoric when teaching translation. English translation is generally a detailed description of a paragraph or a story. Therefore, how an English article translator uses the clever rhetoric application to make the reader feel that the meaning and emotion of the article is particularly important. For example: This idea is very good can be translated as that is a good idea! However, this form of translation is too common, and readers simply do not realize where the "ideas" are. Based on this, they can use decorative words to embellish the translation sentence, and replace good with useful words without changing the original meaning of the sentence. On the clever use of alternative words, make the translated 
sentence has bright spots, and then improve the students' English translation level.

\subsection{Establishment of Supervision and Management Evaluation System for Teachers’ Teaching Level.}

Teaching evaluation plays a decisive role in improving the teaching level of English classroom teachers. Its main role can be reflected in that teachers can fully understand the problems in their own classroom teaching through teaching evaluation, and make timely feedback through classroom teaching information. In this regard, colleges and universities in the construction of teaching evaluation mechanism to achieve a diversified mode, the content and the main body of teaching evaluation to be divided exactly [8].

First of all, English teachers in colleges and universities should fully respect the subjective status of students' classroom teaching in class teaching. Regularly, classmates are allowed to evaluate the performance of classroom teaching in stages, and students' self-learning ability and active learning enthusiasm are tested, and students' teaching is also taught. Evaluation gives a certain amount of instruction.

Secondly, as a comprehensive subject, English translation teaching requires the combination of students' logical thinking ability, language expression ability, reading comprehension ability and many other skills in teaching. This requires teachers to consider the students' needs Ability, comprehensive analysis and evaluation of students in the classroom teaching of the advantages and disadvantages, while affirming student learning advantages, while turning to point out the deficiencies in student learning, prompting students to correct [9].

\section{Conclusion}

The innovation of English translation teaching in colleges and universities based on functional translation theory plays an important role in promoting the improvement of teachers' teaching level, the improvement of classroom teaching efficiency and teaching quality, and the cultivation of students' comprehensive English literacy. In summary, the innovation of college English translation teaching based on the functional translation theory is not only an important embodiment of implementing the people-oriented principle of the scientific development concept, but also the only way to promote students' all-round development.

\section{References}

[1] Yu Honghong. Discussion on the English translation teaching innovation strategy in colleges and universities based on functional translation theory [J]. Journal of Jilin RTV University, 2017(2):121-122.

[2] Huang Siying. Research on College English Teaching Innovation Based on Functional Translation Theory [J]. Journal of Hunan Institute of Science and Technology, 2016(6):151-152.

[3] Wu Kejia. Research on College English Teaching Based on Functional Translation Theory [J]. Literature and Art Life • Late Issue, 2017(5): 65.

[4] Ren Xiaowen. College English Teaching Guided by Functional Translation Theory [J]. Science and Technology Economic Market, 2017(9):218-218.

[5] Shi Xiuchuan. Analysis of Innovative Strategies in College English Translation Teaching under Functional Translation Theory [J]. Campus English (late), 2017(10):30.

[6] Hui Chun. College English Teaching Innovation Strategy under Functional Translation Theory [J]. Journal of Suzhou Education Institute, 2017(3):110-111.

[7] Cong Ji, Tang Chunying. The Enlightenment of the German Functional Translation Theory to Translation Teaching of English Majors [J]. Journal of Liaoning University of Science and Technology, 2017(3):324-326. 
[8] Wang Xiaoyan. Research on College English Teaching Innovation Strategies in Functional Translation [J]. Journal of Suzhou Education College, 2016(5):139-140.

[9] Zhou Daofeng. College English Teaching Innovation Strategy under Functional Translation Theory [J]. Journal of Baoji University of Arts and Sciences (Social Science Edition), 2018(6):163-165. 